\title{
Effect of mood on lexical decisions
}

\author{
DAVID M. CLARK, JOHN D. TEASDALE, DONALD E. BROADBENT, \\ and MARYANNE MARTIN \\ University of Oxford, Oxford, England
}

\begin{abstract}
This experiment investigated the effects of induced elation and depression on lexical decision times for positive, negative, and neutral words. Contrary to prediction, decision times for mood-congruent words were not faster than decision times for mood-incongruent words. Following the lexical decision task and while still in an induced elated or depressed mood, subjects were given a surprise recall test for the words presented during the lexical decision task. Mood-incongruent words tended to be recalled better than mood-congruent words. Several possible explanations of these unexpected findings are discussed.
\end{abstract}

Recent studies have shown that induced mood states have differential effects on the recall of certain positive and negative words. Isen, Shalker, Clark, and Karp (1978) found that recall of previously learned positive personality trait words was greater following success on a computer game than following failure, whereas recall of negative personality trait words was the same in both conditions. These authors interpreted their results in terms of the effects of mood on recall. Teasdale and Russell (in press) presented neutral-mood subjects with a word list containing positive, negative, and neutral personality trait words. A depressed or a happy mood was then induced, and then recall of the previously presented words was tested. The subjects recalled negative trait words better when they were in a depressed mood than when they were in a happy mood, positive trait words better when they were in a happy mood than when they were in a depressed mood, and neutral trait words equally well in the two mood states. Finally, Clark and Teasdale (Note 1) presented neutral-mood subjects with a set of positive and negative trait words and abstract nouns. A depressed or a happy mood was then induced, and then incidental recall of the previously presented words was tested. Consistent with Teasdale and Russell's (in press) findings, the subjects recalled negative trait words better when they were in a depressed mood than when they were in a happy mood and positive trait words better when they were in a happy mood than when they were in a depressed mood. In addition, the differential effect of mood on the recall of trait words was found to be stronger in women than in men, and the recall of positive and negative abstract nouns was not significantly affected by mood.

This research was supported by the Medical Research Council and the Science and Engineering Research Council. The authors are very grateful to Gordon H. Bower, Diane Bray, Gillian Butler, and Andrew Smith for helpful discussions. Requests for reprints should be sent to David M. Clark, Department of Psychiatry, University of Oxford, Oxford OX3 7JX, England.
In attempting to account for these findings, Teasdale (in press), Teasdale and Russell (in press) and Clark and Teasdale (Note 1) have utilized the associative network model of mood and memory (Bower, 1981). This model proposes that emotional states can be represented as nodes in a semantic network model of memory (Anderson, 1976; Anderson \& Bower, 1973). Each emotion node is linked to descriptions of events during which that emotion occurred, as well as to perceptual categories, themes, and words semantically related to it. When the emotion is experienced, activation spreads from the emotion node to other nodes associated with it. As a consequence of this spread of activation, emotions can function as cues for the recall of material that has previously been associated with them. In addition, the spread of activation produced by an emotional state should "prime" perceptual categories related to that emotion.

The present experiment investigated the associative network theory's prediction that emotional states will prime or activate perceptual categories that are related to those states. The perceptual task chosen was lexical decision. In this paradigm, subjects are presented on some trials with a word and on other trials with a nonword. Their task is to decide as fast as possible whether the letter string that they see forms a word or a nonword. For our present purposes, the most important finding in this paradigm relates to what happens when a target word is preceded by a priming word to which the subject does not have to respond. If the word is semantically related to the target word, then lexical decision times are speeded relative to the times in the condition in which the target word is unrelated to the prime. Neely (1977), among others, has argued that a major component of this facilitation effect consists of the spread of activation, through semantic memory, from the node representing the prime word to the nodes representing the target word and other semantically related words. Because the associative network model of mood and memory proposes that activation spreads from emotion nodes to other semantically related nodes, 
one would expect, by analogy with the priming effect, that moods should speed lexical decision times for words that are congruent with them. The present experiment compares the effects of happy and depressed moods on lexical decision times for positive, negative, and neutral words. It was predicted that, relative to a neutral word baseline, lexical decision times for positive words would be faster when subjects were in a happy mood than when they were in a depressed mood, whereas lexical decision times for negative words would be faster when subjects were in a depressed mood than when they were in a happy mood. Previous studies of the effects of mood on recall (Bower, Monteiro, \& Gilligan, 1978; Teasdale \& Russell, in press; Clark \& Teasdale, Note 1) had suggested that the congruent word activating effects of a mood state might be restricted to a relatively small class of emotional words. For this reason, the words used in the lexical decision task here were the same as those that previous studies had shown to be preferentially recalled in mood states congruent with the hedonic tone of the word.

\section{METHOD}

\section{Overview}

The subjects performed a lexical decision task while they were in an induced happy or an induced depressed mood. The word lists for the lexical decision task comprised equal numbers of positive, neutral, and negative personality trait words. The nonwords were made from the words by reversing the position of two internal letters. After they had completed the lexical decision task and while they were still in an induced mood, the subjects were required to recall all of the words that had previously been presented during the lexical decision task.

\section{Subjects}

Twenty-six female student volunteers from Oxford Polytechnic were recruited to take part in an experiment "investigating the effects of mood on various aspects of performance." Twenty subjects met the acceptance criteria for the study (see below). Their mean age was 19.7 years $(\mathrm{SD}=1.0$ years).

\section{Apparatus}

Mood measures. Two types of mood measure were used.

(1) Self-reported mood-The subjects rated their moods with cards bearing 0-100 line scales, on which 0 was labeled "I do not feel at all X" and 100 was labeled "I feel extremely X." For different cards, $X$ was "despondent," "happy," and "anxious." "At this moment" was typed at the top of each card to indicate that it was instantaneous mood that was to be rated.

(2) Count times-The subjects counted from 1 to 10 in their own time. Countings were tape recorded so that the total duration of counting could be measured. Teasdale, Fogarty, and Williams (1980) showed this measure to be sensitive to changes in depressed mood.

Mood induction. A musical mood induction was used (see Clark, in press, for a review).

Words/nonwords. The words used in the lexical decision task were eight pleasant ("kind," "helpful," "pleasant," "considerate," "caring," "loving," "generous," "obliging"), eight neutral ("firm," "proud," "solemn," "bashful," "ordinary," "cautious," "excitable," "changeable"), and eight unpleasant ("rude," "cruel," "impolite," "ungrateful," "mean," "callous," "spiteful," "heartless") personality trait words, equated for word length and frequency. The words "kind," "helpful," "pleasant," "considerate," "rude," "cruel," "impolite," "ungrateful," and "mean" were taken from previous studies that had demonstrated differential effects of mood on the recall of positive and negative trait words (Isen et al., 1978; Teasdale \& Russell, in press; Clark \& Teasdale, Note 1). The remaining pleasant and unpleasant trait words were chosen because of their similarity to the others in those categories. An equal number of nonwords were made up by reversing the position of two internal letters in each of the words. Most nonwords were pronounceable.

\section{Procedure}

The subjects were tested individually. They practiced using the mood scales and were then given 12 practice trials of lexical decision. Neutral nouns were used as word/nonword stimuli and were presented in capitals on a green phosphor video display unit, the display being controlled by a Research Machines $380 \mathrm{Z}$ microcomputer. Each trial consisted of a 1 sec presentation of a fixation point, a $500-\mathrm{msec}$ blank field, and then the presentation of a word/nonword. The subjects responded by pressing one of two buttons, each of which terminated the display. The button under the subjects' left hand was marked "Yes" and was to be pressed if the subjects considered the stimulus to be a word. The button under the subjects" right hand was marked "No" and was to be pressed if the subjects considered the stimulus to be a nonword. Following the practice trials, the subjects rated their moods and counted from 1 to 10 . They were then given instructions for the musical mood induction. These stressed that the music would not automatically put them into a depressed (or happy) mood and that they would have to try really hard to get into the mood, using whatever means they found effective. After starting the music, the experimenter left the room, to return shortly before the end of the music. When the music had finished, the subjects rerated their moods and again counted from 1 to 10 . It was stressed that the subjects should be honest in their ratings of mood. Next, the subjects performed the lexical decision task. The 48 stimuli were presented in four blocks of trials. In order to maintain the induced mood state throughout the task, the subjects were briefly returned to the mood inductions in the interval between each block of trials. Mood was rerated immediately after each block in order to check that the mood state had been maintained. Each block consisted of 14 trials, with an interval of 4 sec between trials. The first 2 stimuli in each block were a neutral trait word and a nonword made from another neutral trait word. These served as practice items, and the decision times for them were not recorded. For each of the subjects, the positive, neutral, and negative words and nonwords were randomly allocated to the remaining trials in the four blocks, subject to the constraint that for half the subjects meeting the acceptance criterion (see below), the longest 50\% of the stimuli were presented in the first two blocks, and for the remaining criterion subjects, the shortest $50 \%$ of stimuli were presented in the first two blocks. Following the completion of the fourth block of trials and a subsequent reinduction of mood, the subjects rated their moods and then were given a surprise recall test for the words presented during the lexical decision task.

Next, the subjects returned to normal mood and filled in a postexperiment questionnaire. This checked whether recall had been truly incidental and also asked subjects to report honestly on whether or not their moods had changed during the moodinduction procedure.

Because the focus of the study was on the effects of experimentally manipulated mood states, a mood-change criterion was defined before the experiment began. The subjects were considered to have responded to the mood-induction procedure if their self-ratings of mood changed in the predicted direction and they stated in the postexperiment questionnaire that their moods had genuinely changed. The subjects were randomly allocated to happy and depressed mood inductions until there were 10 subjects meeting this criterion in both the happy and depressed induction groups. The subjects who failed to meet the mood change criterion were excluded from analysis. 


\section{RESULTS}

\section{Differences in Mood Between \\ Experimental Groups}

The various mood measures were each subjected to a two-way analysis of variance (induction by measurement occasion). In all cases, this produced a significant interaction between type of induction and measurement occasions: self-reported happiness $[\mathrm{F}(6,108)=28.4$, $\mathrm{p}<.001]$; self-reported despondency $[\mathrm{F}(6,108)=19.2$, $\mathrm{p}<.001]$; self-reported anxiety $[\mathrm{F}(6,108)=3.3$, $\mathrm{p}<.01]$; count times $[\mathrm{F}(1,18)=8.5, \mathrm{p}<.01]$. Tukey tests indicated that there were no significant differences between the two induction groups prior to the induction. On all occasions after the induction, the depressed group differed significantly, and in the expected direction, from the happy group on all measures except anxiety. Differences in self-reported anxiety were in the expected direction but were nonsignificant. Once a mood state had been induced, there was no tendency for it to diminish as the experiment progressed. Table 1 presents the immediately postinduction means for the depressed and happy induction groups.

\section{Effects of Mood on Lexical Decisions}

The means and standard deviations for each subject's correct responses to each type of word and nonword were calculated. Scores falling above or below 2 SDs from their respective means were discarded from further analysis.

Table 2 shows the mean decision times in each mood for each type of trait word. These data were subjected to a two-way analysis of variance: mood (happy, depressed) by word pleasantness (positive, neutral, negative). Contrary to prediction, there was no significant interaction between mood and word pleasantness $[F(2,36)=.44, p=.65]$. In addition, there were no significant main effects of mood or word pleasantness.

Table 2 also shows the mean error rates for the three types of trait word. Again, a two-way analysis of variance failed to produce any significant main effects or a significant interaction between mood and word pleasantness. The mean decision times and error rates for positive, neutral, and negative nonwords were also subjected

Table 1

Means for Postinduction Mood Measures in Happy and Depressed Induction Groups

\begin{tabular}{lcc}
\hline \multirow{2}{1}{ Measure } & \multicolumn{2}{c}{ Induction } \\
\cline { 2 - 3 } & Happy & Depressed \\
\hline Happiness & 83.0 & 39.0 \\
Despondency & 4.0 & 54.0 \\
Anxiety & 11.9 & 39.0 \\
Count Times (in Seconds) & 6.3 & 8.4 \\
\hline
\end{tabular}

Note-Measures were taken immediately after the first musical mood induction. Happiness, despondency, and anxiety were rated on a scale of 0 to 100 . Count times were the times required for counting from 1 to 10 .
Table 2

Mean Word Decision Times (in Milliseconds) and Percent Errors for Lexical Decision Task

\begin{tabular}{cccccr}
\hline & \multicolumn{4}{c}{ Induction } \\
\cline { 2 - 3 } \cline { 5 - 6 } $\begin{array}{c}\text { Type of } \\
\text { Word }\end{array}$ & \multicolumn{2}{c}{ Happy } & & \multicolumn{2}{c}{ Depressed } \\
\cline { 2 - 3 } \cline { 5 - 6 } & Time & PE & & Time & PE \\
\hline Positive & 881.4 & 2.5 & & 895.9 & 5.0 \\
Neutral & 940.1 & 6.3 & & 1015.5 & 7.5 \\
Negative & 891.4 & 6.3 & & 979.3 & 10.0 \\
\hline
\end{tabular}

Note-PE = percent error .

to mood by pleasantness analyses of variance. These also failed to show any significant interactions between mood and pleasantness.

In order to establish that subjects in the present study were not responding to the lexical decision task in an unusual fashion, two further analyses were conducted. First, the across-word correlation between a word's length and its mean lexical decision time was computed. Lexical decision times usually increase with word length (Whaley, 1978), and this effect was replicated in the present study $[\mathrm{r}(22)=.56, \mathrm{p}<.01]$. Second, word and nonword lexical decision times were compared. Previous studies had often found that words are responded to faster than nonwords (Whaley, 1978), and this was also the case in the present study $[\mathrm{F}(1,18)$ $=9.5, \mathrm{p}<.01]$.

\section{Effects of Mood on Recall}

Following the lexical decision task, the subjects were given a surprise recall test. Postexperiment questionnaire responses indicated that none of the subjects suspected that they would be asked to recall words from the lexical decision task. Table 3 shows the mean numbers of positive, neutral, and negative trait words recalled in each mood. These were subjected to a two-way (mood by word pleasantness) analysis of variance. This produced a significant main effect of pleasantness $[F(2,36)$ $=8.31, \mathrm{p}<.01]$ and a trend towards a significant interaction between mood and word pleasantness $[F(2,36)=3.19, p=.053]$. In order to investigate the generalizability of these results, a second two-way analysis of variance was conducted, substituting words for subjects as the random factor. This again produced a significant main effect of pleasantness $[F(2,21)=3.71$, $\mathrm{p}<.05$ ] . In addition, the interaction between mood and word pleasantness was also significant $[\mathrm{F}(2,21)=3.85$, $\mathrm{p}<.05]$. Tukey tests indicated that the main effect of pleasantness arose because positive and negative words did not differ in their level of recall but both were more likely to be recalled than were neutral words. Inspection of Table 3 shows that the trend towards an interaction between mood and word pleasantness was in the opposite direction from that predicted. More negative than positive words were recalled in the happy mood. Conversely, more positive than negative words were recalled 
Table 3

Mean Number of Positive, Neutral, and Negative Words Recalled in Each Mood

\begin{tabular}{ccc}
\hline & \multicolumn{2}{c}{ Induction } \\
\cline { 2 - 3 } Type of Word & Happy & Depressed \\
\hline Positive & 2.1 & 2.7 \\
Neutral & 1.5 & 0.9 \\
Negative & 3.3 & 2.0 \\
\hline
\end{tabular}

in the depressed mood. A post hoc comparison, excluding neutral trait words, revealed a significant difference between the two moods in the number of positive minus negative words recalled $[\mathrm{t}(18)=2.56, \mathrm{p}<.05]$.

\section{DISCUSSION}

Contrary to prediction, decision times for mood-congruent words were not faster than decision times for mood-incongruent words. Instead, the two types of words showed similar decision times in both the happy and depressed induction groups. These results are a marked contrast to the results reported in previous studies of the effects of mood on recall of positive and negative words. Teasdale and Russell (in press) and Clark and Teasdale (Note 1) studied essentially the same words as those used in the present experiment, and both sets of investigators found significantly better recall for mood-congruent than for mood-incongruent words.

Gerrig and Bower (1982) recently reported failing, in two experiments, to find lower perceptual thresholds for moodcongruent than for mood-incongruent words. In attempting to account for their results, Gerrig and Bower suggested that mood will only influence perceptual tasks that involve the retrieval of the affective properties of words "but will not influence 'lower level' pattern identification processes that reflect highly overlearned, automated skills"'(p. 200). Word/nonword classification could be performed on the basis of fairly low-level processes, and, therefore, Gerrig and Bower's hypothesis could also be applied to the present results. However, semantic priming effects have repeatedly been observed in lexical decision experiments. It is therefore necessary for the associative network model of mood and memory to account for why the spreading activation produced by a semantic prime influences lexical decision times while the presumed spreading activation produced by an emotional state does not. There are several possible explanations for this apparent discrepancy. First, the facilitation produced by a priming stimulus is likely to be proportional to the strength of association between priming stimulus and target word. It is therefore possible that the personality trait words used in the present experiment were insufficiently strong associates of their congruent mood states for a facilitation effect to be observed. Second, semantic information about a word and information about an individual's emotional experience with that word may be stored separately, with the former being accessed more quickly but the latter being more likely to be activated by a congruent mood state. The quickly accessed semantic and presemantic information could be used for lexical decisions; hence, we would not expect a mood-congruency effect on such decisions. Finally, it could be that mood-congruency effects only occur in paradigms in which the subject is not presented with the emotional stimulus under investigation but instead has to generate it, such as in free recall and word association.

In contrast with previous studies of the effects of mood on recall, the subjects in the present study tended to recall more mood-incongruent than mood-congruent words. The most obvious difference in procedure between the present and previous studies is the mood that subjects were in during encoding. In previous studies, the subjects were in a neutral mood during encoding, whereas in the present experiment, the subjects were in a depressed or a happy mood during encoding and this mood was maintained during retrieval. Being in a depressed or a happy mood during encoding could produce the present results if it led to greater rehearsal of mood-incongruent than of mood-congruent words. The subjects reported that, during the interval between their responses and the next stimulus, they thought about words from the lexical decision task and checked whether they had responded correctly. If mood increases the accessibility of mood-congruent words during this interval, then this checking process could be completed more quickly for mood-congruent words than for mood-incongruent words. In this way, subjects would be aware of mood-incongruent words longer than they would be aware of mood-congruent words. This post hoc explanation clearly requires testing. However, it has the merit of explaining the unexpected superior recall of mood-incongruent words in terms of the previously established greater accessibility of mood-congruent words.

\section{REFERENCE NOTE}

1. Clark, D. M., \& Teasdale, J. D. Constraints on the effects of mood on memory. Manuscript submitted for publication, 1983.

\section{REFERENCES}

Anderson, J. R. Language, memory and thought. Hillsdale, N.J: Erlbaum, 1976.

Anderson, J. R., \& Bower, G. H. Human associative memory. Washington, D.C: Winston, 1973.

Bower, G. H. Mood and memory. American Psychologist, 1981, 36, 129-148.

Bower, G. H., Monteiro, K. P., \& Gilligan, S. G. Emotional mood as a context for learning and recall. Journal of Verbal Learning and Verbal Behavior, 1978, 17, 573-583.

Clark, D. M. On the induction of depressed mood in the laboratory: Evaluation and comparison of the Velten and musical procedures. Advances in Behaviour Research and Therapy, in press.

GerRig, R. J., \& Bower, G. H. Emotional influences on word recognition. Bulletin of the Psychonomic Society, 1982, 19, 197-200.

Isen, A. M., Shalker, T. E., Clark, M., \& Karp, L. Affect, accessibility of material in memory, and behavior: A cognitive loop? Journal of Personality and Social Psychology, 1978, 36, 1-12.

NEELY, J. H. Semantic priming and retrieval from lexical memory: Roles of inhibitionless spreading activation and limited capacity attention. Journal of Experimental Psychology: General, 1977, 106, 226-254.

Tensdale, J. D. Affect and accessibility. Philosophical Transactions of the Royal Society of London (Series B), in press.

Teaspale, J. D., Fogarty, S. J., \& Williams, J. M. G. Speech rate as a measure of short-term variation in depression. British Journal of Social and Clinical Psychology, 1980, 19 271-278.

Teasdale, J. D., \& Russell, M. L. Differential effects of induced mood on recall of positive, negative and neutral words. British Journal of Clinical Psychology, in press.

Whaley, C. P. Word-nonword classification time. Journal of Verbal Learning and Verbal Behavior, 1978, 17, 143-154.

(Received for publication April 4, 1983.) 